\title{
Revisitando a dinâmica trimestral do investimento no Brasil: 1996-2012
}

\author{
Revisiting the quarterly investment \\ dynamics in Brazil: 1996-2012
}

CLÁUDIO H. M. DOS SANTOS*, ANDRÉ DE MELO MODENESI**, GABRIEL SQUEFF $^{* * *}$, LUCAS VASCONCELOS*; MONICA MORA $*$, THAIS FERNANDES $\cdots$, THIAGO MORAES ${ }^{+}$, ICARDO SUMMA ${ }^{++}$, JULIA BRAGA ${ }^{+++}$

\begin{abstract}
RESUMO: Este texto discute os dados e os principais fatos estilizados da dinâmica da formação bruta de capital fixo (FBCF) no Brasil após 1995. Apresenta, ademais, especificações econométricas para a dinâmica trimestral da FBCF no período 1996-2012 que levantam hipóteses causais ainda relativamente inexploradas na literatura. Os dados apresentados evidenciam as dinâmicas distintas da FBCF em máquinas e equipamentos e construções - e, consequentemente, o papel fundamental da primeira variável na dinâmica da FBCF total da economia. As estimativas apresentadas sugerem choques cambiais, nos preços internacionais de commodities e na FBCF pública como mecanismos causais da dinâmica trimestral da FBCF brasileira.

PALAVRAS-CHAVE: investimento brasileiro; contas nacionais; modelos de séries temporais.

ABSTARCT: This text discusses the data on and the stylized facts of the dynamics of Brazil's gross fixed capital formation (GFCF) since 1995. It also presents new econometric specifications for the quarterly dynamics of the Brazilian GFCG in the 1996-2012 years that suggest new causal interpretations to the problem at hand. The data make clear the different dynamics of the GFCF in dwellings and other buildings and structures and in machinery and equipment - and, as a consequence, the crucial role of the latter variable in the dynamics of Brazilian aggregate investment. The econometric specifications, in turn, suggest shocks in
\end{abstract}

\footnotetext{
* Técnico de Planejamento e Pesquisa da Diretoria de Estudos Macroeconômicos (DIMAC) do IPEA, e-mail claudio.santos@ipea.gov.br. ** Professor da Universidade Federal do Rio de Janeiro (UFRJ), Rio de Janeiro, RJ - Brasil e pesquisador do CNPq., e-mail: amodenesi@gmail.com. *** Técnico de Planejamento e Pesquisa da Diretoria de Estudos Macroeconômicos (DIMAC) do IPEA, e-mail gabriel.squeff@ipea.gov. br. • Técnico de Planejamento e Pesquisa da Diretoria de Estudos Macroeconômicos (DIMAC) do IPEA, e-mail: lucas.vasconcelos@ipea.gov.br. •• Técnica de Planejamento e Pesquisa da Diretoria de Estudos Macroeconômicos (DIMAC) do IPEA, E-mail: monicamora.ipea@gmail.com. $\cdots$ Bolsista do Programa de Mobilização da Competência Nacional para Estudos sobre o Desenvolvimento (PROMOB) do IPEA.email: thais.teixeira@ipea.gov.br. ${ }^{+}$Economista da Petrobras, e-mail: thiago.moraes@petrobras.com.br. ${ }^{++}$ Professor da Universidade Federal do Rio de Janeiro, (UFRJ), Rio de Janeiro, RJ - Brasil, e-mail: ricardo. summa@ie.ufrj.br. ${ }^{++}$Professora da Universidade Federal Fluminense (UFF), Rio de Janeiro, RJ - Brasil, e-mail jbraga@id.uff.br. Submetido: 13/setembro/2013; Aprovado: 13/fevereiro/2015.
} 
the real exchange rate international commodity prices and public investment as underlying causal mechanisms of the quarterly behavior of the Brazilian GFCF.

KEYWORDS: Brazilian investment; national accounts; time series models.

JEL Classification: C22; C82; E22.

\section{INTRODUÇÃO}

Poucos temas são mais debatidos em macroeconomia, ou mais importantes para a definição das políticas macroeconômicas, quanto os determinantes do investimento agregado de uma economia capitalista.

No Brasil o debate não é menos acirrado. E não são poucos os que defendem que uma taxa de câmbio desvalorizada seria essencial para estimular o investimento privado. Com efeito, um conjunto expressivo de economistas identifica a ocorrência de um processo de desindustrialização na economia brasileira associada à chamada Doença Holandesa (Bresser-Pereira, 2008, 2010a, 2010b, por exemplo). A existência de uma "tendência cíclica à sobreapreciação da taxa de câmbio" tornaria, de acordo com estes autores, a taxa de câmbio de equilíbrio "corrente" cronicamente inferior à taxa de câmbio de equilíbrio "industrial”, que assegura a rentabilidade/competitividade das empresas. Isso prejudicaria o desempenho do setor industrial comprometendo, assim, o investimento e, em última análise, o próprio desenvolvimento econômico.

Este texto visa contribuir para o debate sobre os determinantes do investimento no Brasil contemporâneo de três maneiras. Primeiramente, apresentando e discutindo, na segunda seção, os dados disponíveis sobre a formação bruta de capital fixo (FBCF) da economia brasileira e os principais fatos estilizados revelados pelos dados no período 1996-2012. Em segundo lugar, na terceira seção, discutindo as características gerais da literatura econométrica sobre o tema no Brasil. E, por fim, na quarta seção, apresentando especificações para a dinâmica trimestral (de diferentes medidas) da FBCF brasileira no período 1996-2012 que se ajustam bem aos dados e levantam hipóteses causais ainda relativamente inexploradas na literatura aplicada sobre o tema - sublinhando, em particular, o papel desempenhado pelo cenário internacional na dinâmica recente da FBCF (e da própria taxa de câmbio) brasileira(s). A quinta e última seção, por sua vez, resume e contextualiza as principais conclusões das seções anteriores.

\section{OS DADOS DISPONÍVEIS: ASPECTOS METODOLÓGICOS E FATOS ESTILIZADOS}

Esta seção tem dois objetivos fundamentais: (i) aprofundar a sabedoria sobre a dinâmica recente da FBCF no Brasil a partir de dados pouco convencionais sobre a FBCF das administrações públicas e das (despesas de investimento das) empresas estatais (federais) e sobre a desagregação da FBCF em construções e máquinas e 
equipamentos; e (ii) qualificar o debate sobre estes temas a partir de uma análise sobre o que exatamente é medido nos dados da FBCF brasileira ${ }^{1}$.

\section{Aspectos metodológicos e operacionais}

De acordo com ambos os sistemas de contas nacionais (SNA de "Systems of National Accounts") de 1993 e 2008 produzidos conjuntamente pela ONU, o FMI, a OCDE, a Comissão Europeia e o Banco Mundial, a FBCF de um dado agente econômico ou setor institucional "[...] é medida pelo valor total [...] das aquisições menos cessões de ativos fixos durante um determinado período contábil mais alguns gastos em serviços que adicionam valor a ativos não produzidos".

O sistema de 1993 (SNA 1993) - a base do atual sistema de contas nacionais brasileiro (referência 2000) - determina que o cálculo da FBCF deve ser feito com base nos valores que constam nos balanços patrimoniais dos demandantes referentes à aquisição de novos ativos fixos, de vida útil superior a um ano, assim como os gastos em decorrência de melhorias realizadas que prolonguem a vida útil ou aumente a capacidade produtiva de ativos já incorporados ao balanço. Os ativos fixos podem ser comprados de terceiros ou produzidos por conta própria. $\mathrm{Na}$ situação de compra, a valoração dos ativos deve utilizar os preços de aquisição; já na produção própria, os bens devem ser avaliados segundo seus próprios custos de produção. Por fim, o SNA 1993 destaca que a contabilização da FBCF deve ocorrer no momento em que a propriedade é transferida e o ativo fixo é incorporado ao balanço dos agentes adquirentes - por oposição ao momento em que o ativo é produzido.

As contas nacionais brasileiras (ref. 2000) incluem no conceito de FBCF fundamentalmente ativos tangíveis e, portanto, subestimam a FBCF da economia tal como definida nos SNAs 1993 e 2008. Com efeito, as contas brasileiras classificam como FBCF fundamentalmente "[...] bens imóveis (construções residenciais, comerciais, industriais, obras de infra-estrutura, etc.) e móveis (meios de transporte, máquinas, equipamentos e outros bens de capital)", além do "valor dos serviços ligados à instalação dos bens de capital, dos bens e serviços incorporados aos terrenos, das melhorias que elevam a vida útil dos ativos existentes, assim como o valor dos gastos inerentes à transmissão de propriedades de terrenos, edifícios e outros bens de capital existentes" (IBGE, 2008, p. 35). Finalmente, "são considerados, também, no total da [...] [FBCF] os valores das novas culturas permanentes, das novas matas plantadas, das variações do efetivo de bovinos destinados à produção de leite e reprodução, baseados na estrutura verificada no Censo Agropecuário” (ibid, p. 65).

Os dados anuais da FBCF aparecem de duas maneiras diferentes nas contas referência 2000. Primeiramente, na chamada Tabela de Usos, na qual a demanda total nominal da economia aparece desagregada por produto. As contas referência 2000

\footnotetext{
${ }^{1} \mathrm{O}$ conhecimento destes detalhes técnicos e institucionais nos será particularmente útil, ainda, na tentativa de identificação de relações de causalidade na quarta seção deste trabalho.
} 
estão formatadas em 110 produtos, dos quais apenas 19 são passíveis de demanda (final) na forma de FBCF - de modo que a FBCF total da economia pode ser apresentada na forma de um vetor de dezenove (valores de) produtos na Tabela de Usos.

Em segundo lugar, os dados da FBCF aparecem nas chamadas contas econômicas integradas (CEI) distribuídos entre os setores institucionais demandantes, quais sejam: empresas (financeiras e não financeiras), famílias, instituições sem fins lucrativos e administração pública (APU).

Naturalmente, os valores da oferta total dos bens de investimento (produzidos e importados) e da demanda (absorção interna e exportações) por estes bens devem ser idênticos. Sendo assim, poder-se-ia, em tese e com os devidos ajustes (ver adiante), chegar ao valor da FBCF por dois possíveis caminhos, quais sejam: pela ótica da produção e importação (oferta) de bens de investimento e pela ótica da demanda por estes bens, sejam relativos às atividades econômicas ou aos setores institucionais.

Na prática, o cálculo da FBCF brasileira "toma por base, de um lado, a oferta dos bens e serviços que, por sua natureza, se destinam à [...] [FBCF]; de outro, a análise das informações relativas aos investimentos produtivos realizados pelos setores institucionais, ou seja, a demanda interna de bens de capital" (IBGE, 2008, p.66). Para o cálculo da oferta doméstica são utilizadas as pesquisas estruturais do IBGE - entre as quais se destacam a Pesquisa Anual da Indústria (PIA), Pesquisa Anual de Serviços (PAS) e Pesquisa Anual da Indústria da Construção (PAIC) - enquanto que as estatísticas de comércio exterior são utilizadas para calcular a oferta importada de bens de capital. Para o cálculo da demanda, o IBGE usa informações sobre os fluxos anuais de aquisição de produtos classificados como FBCF por cada um dos setores institucionais. No caso das empresas (financeiras e não financeiras) e instituições sem fins lucrativos são utilizados dados da Declaração de Informações Econômico-Fiscais da Pessoa Jurídica (DIPJ) fornecidos pela Receita Federal. No caso da FBCF das famílias, que corresponde basicamente a produtos da construção e máquinas de uso agrícola, são utilizadas informações das Pesquisas Nacional por Amostra de Domicílios e de Orçamentos Familiares (PNAD e POF, respectivamente). Por fim, a fonte para as estimativas da demanda de investimentos na agricultura e na pecuária é o Censo Agropecuário e, no caso dos investimentos da APU, são utilizados dados de investimentos que constam nos Balanços Orçamentários dos diferentes níveis de governo (federal, estaduais e municipais).

O cálculo da FBCF pelo IBGE pressupõe o cálculo do chamado "consumo aparente" dos produtos demandados na forma de FBCF, i.e. uma estimativa da oferta total dos bens de investimento destinada ao mercado interno dada pela soma da produção doméstica e das importações dos bens de investimento subtraídas da parcela da produção vendida ao mercado externo, ou seja, as exportações destes ativos.

Cumpre lembrar, no entanto, que o valor do consumo aparente não pode ser usado diretamente para o cômputo da FBCF. Isto porque o valor da produção doméstica total dos bens de investimento inclui os valores da parcela da produção destinada ao consumo intermediário das atividades econômicas e da parcela referente à utilização destes bens nos outros componentes da demanda interna final que não a FBCF. Assim, para calcular o valor total de FBCF brasileira com base na 
ótica da oferta dos bens de investimento, o IBGE exclui as rubricas citadas, evitando problemas de dupla contagem e/ou de classificação.

Para algumas categorias de produtos - notadamente "construção, máquinas e equipamentos, automóveis, móveis, etc" (IBGE, 2008, p. 66) - as informações sobre a demanda de bens de capital dos setores institucionais são utilizadas para determinar a destinação da oferta total de bens de capital e, por esta via, o valor final da FBCF. No mais das vezes, entretanto, a destinação da produção é determinada pela análise artesanal dos dados de oferta produto a produto "[...] de modo a separar as partes do produto que efetivamente têm como uso a formação bruta de capital fixo, como a fabricação de máquinas e serviços de instalação e montagem, daquelas que têm como destino o consumo intermediário, como partes e peças, e os serviços referentes à manutenção e reparação de máquinas" (ibid).

A prevalência de dados de oferta é ainda maior no caso das estimativas trimestrais da formação bruta de capital fixo total da economia publicadas pelo IBGE nas contas nacionais trimestrais. É fato que o valor anualizado das referidas estimativas é igual ao valor publicado nas contas nacionais anuais nos anos em que estas estão disponíveis. Mas para os anos em que contas nacionais anuais não estão disponíveis e para o cálculo da sazonalidade intra-anual dos dados anuais quando estes estão disponíveis são utilizados dados (de oferta) da Pesquisa Industrial Mensal (PIM/PF) e os dados de fluxos mensais de importações e exportações, cujos dados originais são registrados pela Secretaria de Comércio Exterior (SECEX). Esse último fato cumpre um papel importante na estratégia de identificação utilizada na quarta parte desse texto.

\section{O que dizem os dados disponíveis sobre a dinâmica recente da FBCF no Brasil?}

A última divulgação das contas nacionais anuais referência 2000 se deu em 2011 com dados relativos ao ano de 2009. Por outro lado, as novas contas nacionais referência 2010 estão previstas para o final de 2014. Daí que dados oficiais sobre a composição da FBCF por produto e a desagregação da FBCF por setor institucional estão disponíveis apenas até o ano de 2009. Apenas as contas trimestrais referência 2000 continuaram sendo publicadas no biênio 2012-2013, ainda que desde 2010 sem o benefício das revisões anuais feitas a partir da divulgação dos dados anuais finais. É de se esperar, entretanto, que os dados atualmente disponíveis para o período pós-2010 sejam submetidos a revisões ainda mais fortes do que os dados disponíveis para o período pré-2010 quando da publicação das contas nacionais referência 2010.

O que dizem os dados anuais oficiais (referência 2000) disponíveis?

A Tabela 1 apresenta os dados da desagregação da FBCF por setor institucional para o período 2000-2009. 
Tabela 1: FBCF por setor institucional em \% do PIB

\begin{tabular}{|l|c|c|c|c|c|c|c|c|c|c|}
\hline & 2000 & 2001 & 2002 & 2003 & 2004 & 2005 & 2006 & 2007 & 2008 & 2009 \\
\hline $\begin{array}{l}\text { Empresas não } \\
\text { financeiras }\end{array}$ & $10,23 \%$ & $10,56 \%$ & $9,91 \%$ & $9,35 \%$ & $9,97 \%$ & $9,92 \%$ & $9,93 \%$ & $10,87 \%$ & $12,26 \%$ & $10,73 \%$ \\
\hline $\begin{array}{l}\text { Empresas } \\
\text { financeiras }\end{array}$ & $0,20 \%$ & $0,09 \%$ & $0,08 \%$ & $0,04 \%$ & $0,13 \%$ & $0,15 \%$ & $0,13 \%$ & $0,14 \%$ & $0,14 \%$ & $0,13 \%$ \\
\hline APU & $1,81 \%$ & $1,99 \%$ & $2,06 \%$ & $1,51 \%$ & $1,72 \%$ & $1,75 \%$ & $2,04 \%$ & $2,10 \%$ & $2,45 \%$ & $2,57 \%$ \\
\hline Famílias & $4,36 \%$ & $4,09 \%$ & $4,14 \%$ & $4,23 \%$ & $4,13 \%$ & $3,93 \%$ & $4,14 \%$ & $4,14 \%$ & $4,06 \%$ & $4,43 \%$ \\
\hline $\begin{array}{l}\text { Instituições } \\
\text { sem fins de } \\
\text { lucro a serviço } \\
\text { das famílias }\end{array}$ & $0,21 \%$ & $0,30 \%$ & $0,20 \%$ & $0,15 \%$ & $0,15 \%$ & $0,19 \%$ & $0,19 \%$ & $0,19 \%$ & $0,20 \%$ & $0,21 \%$ \\
\hline Total & $16,80 \%$ & $17,03 \%$ & $16,39 \%$ & $15,28 \%$ & $16,10 \%$ & $15,94 \%$ & $16,43 \%$ & $17,44 \%$ & $19,11 \%$ & $18,07 \%$ \\
\hline
\end{tabular}

Fonte: IBGE: Contas nacionais anuais.

Percebe-se que, na média de 2000 a 2009, as empresas não financeiras responderam por pouco mais de $60 \%$ da FBCF total da economia e as famílias e o governo por cerca de um quarto e um oitavo, respectivamente, deste total. Para os nossos propósitos imediatos cumpre ressaltar que a mudança no patamar da FBCF medida em \% do PIB verificada entre 2005 e 2008 (de $16 \%$ para 19\%) se deveu crucialmente à elevação nas taxas de investimento das empresas não financeiras e das administrações públicas (de mais de $2 \%$ do PIB no primeiro caso e $0,7 \%$ do PIB no segundo). História similar pode ser contada para o período 2000-2008, ainda que o crescimento da FBCF neste caso tenha sido um pouco menor (saindo de $16,8 \%$ para $19,11 \%$ do PIB). A queda verificada em 2009 , por sua vez, se explica pelos reflexos, no Brasil, da crise mundial que se seguiu à falência do banco Lehman Brothers em setembro de 2008.

Os dados subestimam o papel do estado brasileiro na FBCF total da economia. Isto ocorre porque as empresas estatais "independentes" - i.e., aquelas nas quais as receitas próprias (por oposição a transferências do governo) correspondem a mais de $50 \%$ das receitas totais - não estão incluídas no conceito de APU. Com efeito, de acordo com IBGE (2008, p. 84), este último conceito inclui: i) órgãos da administração direta e indireta dos três níveis de governo; ii) empresas estatais com funções típicas de governo e financiadas primordialmente por transferências [do orçamento público] (em um percentual superior a 50\%); e iii) o sistema para- estatal, financiado por contribuições compulsórias (Sistema S; Conselhos profissionais) e fundos de caráter público (como o Fundo de Garantia do Tempo de Serviço e o fundo remanescente do Programa de Integração Social e Programa de Formação do Patrimônio do Servidor Público - PIS-PASEP). Daí que os valores da FBCF da Petrobras e do Banco do Brasil, por exemplo, são contabilizados respectivamente como FBCF das "empresas não financeiras" e FBCF das "empresas financeiras" e não como FBCF da APU.

Dito de outro modo, as contas nacionais referência 2000 não publicam dados sobre a FBCF das empresas estatais brasileiras. Tais dados eram divulgados na pesquisa "Finanças Públicas" que, infelizmente, foi descontinuada pelo IBGE em 2007. A última publicação da referida pesquisa foi feita em 2006 com dados rela- 
tivos a 2003 e dava conta que as empresas estatais brasileiras (somadas, incluindo dependentes e não dependentes e financeiras e não financeiras) respondiam por $7,2 \%$ da FBCF total da economia em 2003. Deste montante, cerca de três quartos eram investimentos de empresas da União e um quarto eram investimentos de empresas dos governos subnacionais.

Tabela 2: FBCF em máquinas e equipamentos, construções e outros tipos de produtos - taxas de crescimento anuais e valores em \% da FBCF total da economia

\begin{tabular}{|c|c|c|c|c|c|c|c|}
\hline & \multicolumn{2}{|c|}{ Peso na FBCF total da Economia } & \multicolumn{3}{|c|}{ Taxa de Crescimento do índice de Volume } \\
\hline Ano & Construção & $\begin{array}{c}\text { Máquinas e } \\
\text { Equipamentos }\end{array}$ & Outros & Construção & $\begin{array}{c}\text { Máquinas e } \\
\text { Equipamentos }\end{array}$ & Outros & $\begin{array}{c}\text { FBCF } \\
\text { total }\end{array}$ \\
\hline 2000 & $49,61 \%$ & $42,72 \%$ & $7,67 \%$ & ND & ND & ND & $5,0 \%$ \\
\hline 2001 & $46,48 \%$ & $45,84 \%$ & $7,68 \%$ & ND & ND & ND & $0,4 \%$ \\
\hline 2002 & $47,29 \%$ & $44,33 \%$ & $8,39 \%$ & ND & ND & ND & $-5,2 \%$ \\
\hline 2003 & $44,19 \%$ & $46,80 \%$ & $9,01 \%$ & ND & ND & ND & $-4,6 \%$ \\
\hline 2004 & $43,73 \%$ & $47,90 \%$ & $8,37 \%$ & ND & ND & ND & $9,1 \%$ \\
\hline 2005 & $42,28 \%$ & $49,86 \%$ & $7,85 \%$ & ND & ND & ND & $3,6 \%$ \\
\hline 2006 & $40,42 \%$ & $51,65 \%$ & $7,93 \%$ & ND & ND & ND & $9,8 \%$ \\
\hline 2007 & $38,31 \%$ & $54,11 \%$ & $7,58 \%$ & $5,5 \%$ & $22,0 \%$ & $3,8 \%$ & $13,9 \%$ \\
\hline 2008 & $36,31 \%$ & $56,69 \%$ & $7,00 \%$ & $9,3 \%$ & $18,3 \%$ & $1,7 \%$ & $13,6 \%$ \\
\hline 2009 & $42,29 \%$ & $50,12 \%$ & $7,59 \%$ & $1,0 \%$ & $-12,5 \%$ & $0,4 \%$ & $-6,7 \%$ \\
\hline 2010 & $40,65 \%$ & $52,47 \%$ & $6,89 \%$ & $12,9 \%$ & $30,4 \%$ & $8,0 \%$ & $21,3 \%$ \\
\hline 2011 & $41,36 \%$ & $52,40 \%$ & $6,24 \%$ & $3,9 \%$ & $6,0 \%$ & $-0,4 \%$ & $4,7 \%$ \\
\hline 2012 & $43,75 \%$ & $49,74 \%$ & $6,51 \%$ & $1,9 \%$ & $-9,1 \%$ & $-0,7 \%$ & $-4,0 \%$ \\
\hline
\end{tabular}

Fonte: IBGE: Contas nacionais anuais contas nacionais trimestrais.

Finalmente, os dados da Tabela 2 permitem a conclusão de que a mudança no patamar da taxa de investimento da economia se deu fundamentalmente por conta do aumento do investimento em máquinas e equipamentos - cuja participação na FBCF total atingiu um pico de 56,7\% em 2008 (contra 42,7\% em 2000), retornando a casa dos $50 \%$ em anos recentes. Mais do que isso, apontam que a dinâmica dos investimentos em máquinas e equipamentos (cujo crescimento real no período 2000-2012 foi de 119\%) foi bastante distinta da dinâmica dos investimentos em construções (que cresceram $42 \%$ no mesmo período). As seções seguintes retornam a esse ponto.

O que dizem os dados de alta frequência disponíveis?

O IBGE publica dados sobre a FBCF agregada total da economia a preços correntes e a preços constantes encadeados de 1995 nas contas nacionais trimestrais. Analisado pelo lado da oferta, o dado da FBCF divulgado nas contas trimestrais é o agregado da FBCF em máquinas e equipamentos, construções e outras. Pelo lado da demanda, por sua vez, o dado é igual ao agregado da FBCF das firmas financeiras e não financeiras (inclusive empresas e bancos estatais), das famílias, das instituições sem fins lucrativos e das administrações públicas. 
Dois conjuntos de séries produzidas pelo IPEA permitem um quadro mais desagregado da evolução da FBCF trimestral. Primeiramente, dos Santos et al. (2012) propuseram uma metodologia de estimação em bases mensais da FBCF das administrações públicas (Gráfico 1). Em segundo lugar, Carvalho e Ribeiro (2014) propuseram uma metodologia de estimação de índices de volume da FBCF em máquinas e equipamentos e construções (Gráfico 2).

As séries apresentadas nos gráficos 1-2 aparentam ter sofrido uma inflexão positiva entre 2004 e 2006 e uma inflexão negativa em 2011 - o que também ocorre, como seria de se esperar, com a série da FBCF total da economia (Gráfico 3). Acrescente-se que (i) a série da FBCF em máquinas e equipamentos cresce bem mais e é bem mais reativa ao ciclo econômico do que a série da FBCF em construções, no período 1996-2012; (ii) praticamente todas as séries acima permaneceram estagnadas em níveis reais durante o período 1996-2004, de modo que o crescimento real médio entre 2005 e 2010 (9,6\% para máquinas e equipamentos e 3,8\% para construções) foi bem mais rápido do que o verificado no período 1996-2012; (iii) a série da FBCF das administrações públicas tende a aumentar no final dos mandatos presidenciais (e mesmo de prefeitos ${ }^{2}$ ) e diminuir em anos pós-eleitorais; e (iv) a série da FBCF-APU é calculada pela demanda (Dos Santos et al. 2012) e não (majoritariamente) pela ótica da oferta, como as medidas da FBCF nas contas trimestrais. Este último fato, associado ao significativo peso das empresas estatais na FBCF (Tabela 5 e Gráfico 1), qualifica um pouco a utilidade analítica do conceito de investimento privado calculado pela subtração da FBCF da APU da FBCF total da economia (Gráfico 3).

Gráfico 1: Estimativas da FBCF da APU e das "despesas de investimento" das empresas estatais federais (R\$ bilhões de 1995, deflator da FBCF total, dessazonalizadas) ${ }^{3}$

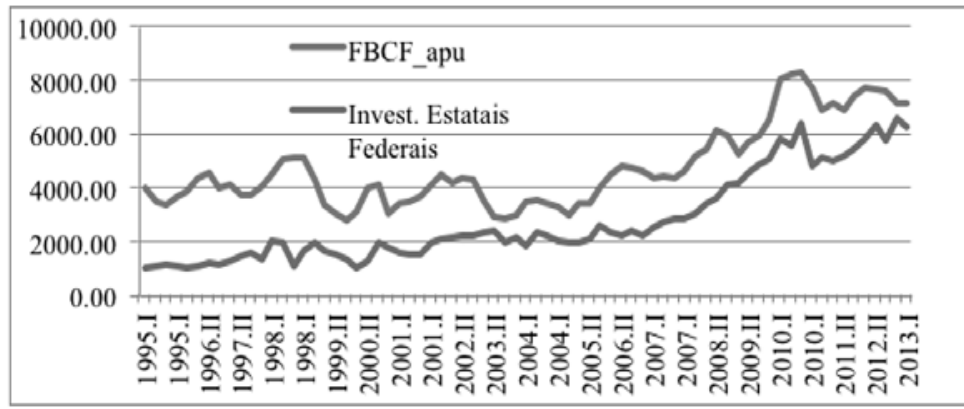

Fonte: IPEA, a partir da metodologia de Dos Santos et al. (2012) e de dados primários do Ministério do Planejamento (no caso das despesas de investimento das empresas estatais federais).

\footnotetext{
${ }^{2}$ Com efeito, na última década a União Federal executou diretamente apenas $22 \%$ do total da FBCFAPU, com os estados e o DF sendo responsáveis por $36 \%$ e os municípios por $42 \%$ deste último total.

${ }^{3}$ A série de "despesas de investimento" - um conceito diferente do de FBCF - das empresas estatais federais é calculada a partir dos dados da execução do "orçamento de investimentos" destas empresas, que faz parte da Lei Orçamentária Anual (LOA) enviada pela União ao Congresso Nacional.
} 
Gráfico 2: Estimativas da FBCF em máquinas e equipamentos e em construção - Índices trimestrais de volume $(1995=100)$ com ajuste sazonal

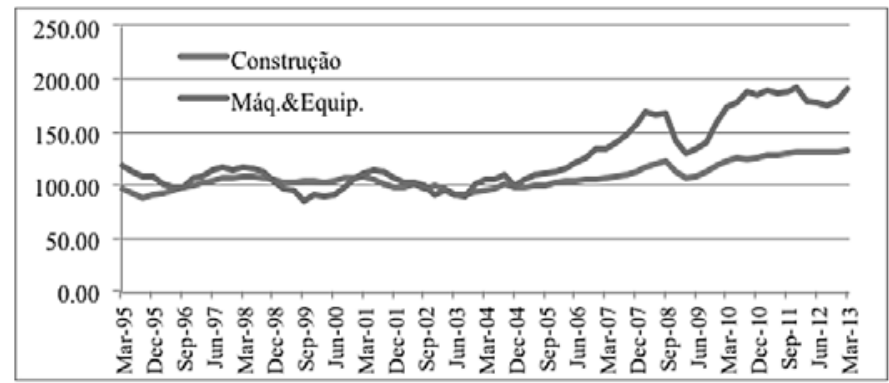

Fonte: Carvalho e Ribeiro (2014).

Gráfico 3: FBCF total, da APU e "privada" em R\$ milhões de 1995 e com ajuste sazonal

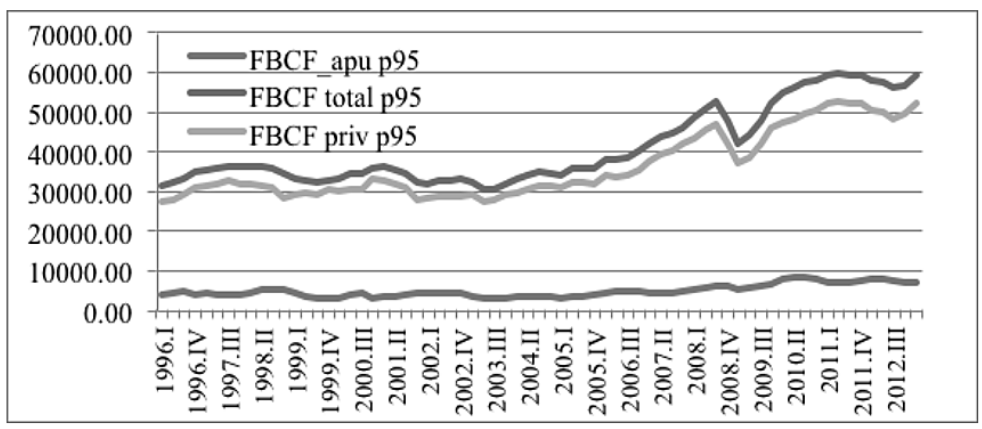

Fontes: IBGE (contas nacionais trimestrais) e IPEA.

\section{Mas quem investe em máquinas e equipamentos e construções?}

A Tabela 3 - baseada nas matrizes de absorção do investimento (MAIs) estimadas para a economia brasileira entre 2000 e 2009 por Miguez et al. $(2013)^{4}-$ reporta a composição da FBCF em 2000 e em 2009 por setor institucional demandante e tipo de produto.

Os dados da Tabela 3 sugerem uma explicação simples para a diferença na dinâmica recente dos investimentos em máquinas e equipamentos e construções, i.e., o fato de as empresas não financeiras serem largamente responsáveis pelos primeiros e as famílias e o governo serem largamente responsáveis pelos últimos.

\footnotetext{
${ }^{4}$ Miguez et al. (2013) refinam e estendem o esforço seminal de Freitas e Dweck (2010).
} 


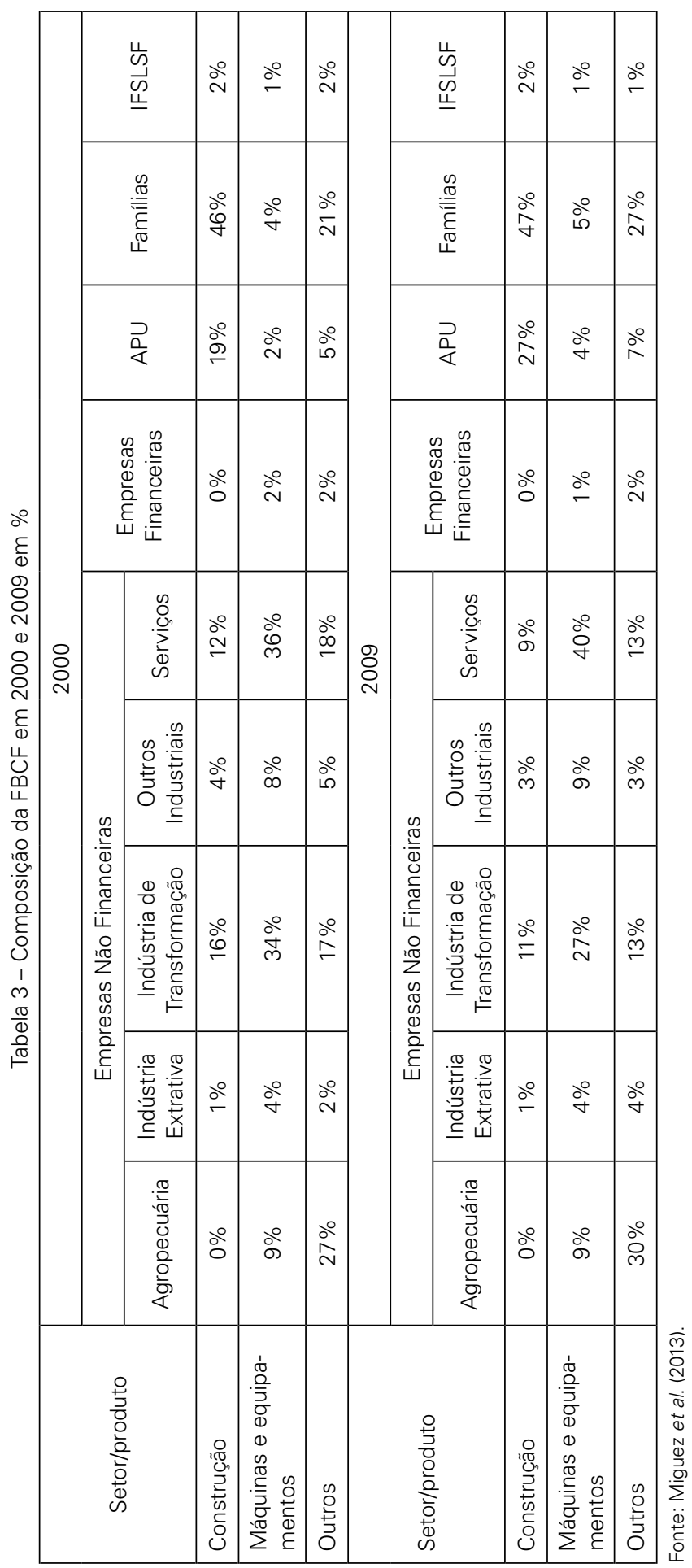


Os dados indicam, ainda, que as mudanças mais significativas de composição da FBCF entre 2000 e 2009 ocorreram na indústria de transformação e nos serviços e na APU. Com efeito, a participação dos serviços na FBCF em construções (em máquinas e equipamentos) diminuiu (aumentou) significativamente no período em questão. A indústria de transformação, por sua vez, apresentou queda em todos os produtos, contribuindo para a redução na participação dos investimentos das empresas não financeiras no período. Finalmente, a aceleração dos investimentos públicos fez com que a participação das APUs no total da FBCF em construções (máquinas e equipamentos) passasse de 19\% (2\%) para 27\% (4\%) entre 2000 e 2009.

\section{COMENTÁRIOS SOBRE A LITERATURA RECENTE COM ESPECIFICAÇÕES ECONOMÉTRICAS SOBRE A DINÂMICA DO INVESTIMENTO NO BRASIL}

Apesar de não serem resenhas propriamente ditas, Dos Santos e Pires (2009) e Luporini e Alves (2010) mapeiam de forma bastante completa os trabalhos empíricos sobre a dinâmica do investimento brasileiro publicados desde a década de 1990 (e mesmo antes) até o início dos anos 2000.

A maioria dos trabalhos citados nestes artigos utiliza a chamada "abordagem da London School of Economics (LSE)" para a modelagem macroeconométrica (Favero, 2001) - i.e., partem do pressuposto que "a teoria econômica sugere as características gerais das relações relevantes, mas a representação precisa do processo gerador dos dados [...] [não] é conhecida de antemão" (ibid., p. 132) e, portanto, deve ser "descoberta”. Daí que, na abordagem LSE, "as formas reduzidas são especificadas primeiro [...] . A hipótese nula relevante é a ausência de sintomas de má especificação, como não normalidade dos resíduos, heterocedasticidade, mudanças paramétricas. Se a hipótese nula não é rejeitada e o sistema em análise for visto como uma representação congruente do processo gerador de dados desconhecido, então é possível lidar com a não estacionaridade dos dados e as propriedades de longo prazo do sistema podem ser identificadas por meio da análise de cointegração" (ibid. $)^{5}$.

Registre-se, ainda, que na prática as variáveis "sugeridas” pelas várias teorias de investimento de acordo com a literatura acima podem ser divididas em sete grupos, quais sejam: medidas de(o) (i) investimento privado; (ii) investimento público; (iii) nível de capacidade da economia; (iv) disponibilidade de crédito; (v) custo de utilização do capital; (vi) incerteza/ambiente externo; e (vii) outras variáveis. A Tabela 4 apresenta um resumo das medidas mais utilizadas em cada caso ${ }^{6}$.

\footnotetext{
${ }^{5}$ Alguns dos trabalhos citados nos dois artigos - notadamente os mais antigos - utilizam abordagens mais próximas da Cowles Comission, anterior à da LSE (Favero, 2001).

${ }^{6}$ A literatura não costuma incluir variáveis distributivas - i.e. taxas/massas de lucro/salários - como variáveis explicativas da dinâmica do investimento. Conte Filho (2008) é a exceção que confirma a regra.
} 
Tabela 4: Aproximações empíricas utilizadas na literatura sobre a dinâmica da FBCF brasileira

\begin{tabular}{|c|c|}
\hline Variável teórica & Aproximações utilizadas \\
\hline $\begin{array}{l}\text { Medidas de investimento } \\
\text { (privado, no mais das } \\
\text { vezes) usadas como } \\
\text { "variável dependente" }\end{array}$ & $\begin{array}{l}\text { FBCF total das contas nacionais anuais menos FBCF da APU; } \\
\text { FBCF total das contas nacionais menos FBCF da APU menos medidas } \\
\text { da FBCF das empresas estatais federais; } \\
\text { FBCF total da economia em máquinas e equipamentos; } \\
\text { FBCF total da economia em construções. }\end{array}$ \\
\hline $\begin{array}{l}\text { Medidas de investimento } \\
\text { público }\end{array}$ & $\begin{array}{l}\text { FBCF da APU das contas nacionais anuais; } \\
\text { FBCF da APU somada a medidas da FBCF das empresas estatais. }\end{array}$ \\
\hline $\begin{array}{l}\text { Medidas do nível de } \\
\text { atividade econômica }\end{array}$ & PIB; nível de utilização da capacidade instalada (NUCI-FGV). \\
\hline $\begin{array}{l}\text { Medidas de disponibilidade } \\
\text { de crédito }\end{array}$ & $\begin{array}{l}\text { Desembolsos do BNDES; Operações de crédito do sistema financeiro } \\
\text { ao setor privado (Banco Central) }\end{array}$ \\
\hline $\begin{array}{l}\text { Medidas do custo de } \\
\text { utilização do capital ou de } \\
\text { bens de capital }\end{array}$ & $\begin{array}{l}\text { Taxas de juros (Selic, TJLP) reais; taxa swap pré-DI de } 360 \text { dias; razão } \\
\text { entre o IPA-DI (bens de produção) e o IGP-DI; razão entre o deflator da } \\
\text { FBCF e o deflator do PIB; taxa de câmbio; taxas de juros (reais, supõe- } \\
\text {-se) dos Certificados de Depósito Bancário (CDBs). }\end{array}$ \\
\hline $\begin{array}{l}\text { Medidas de incerteza / } \\
\text { ambiente externo }\end{array}$ & $\begin{array}{l}\text { Prêmio de risco-país; razão entre o serviço da dívida externa e o PIB; } \\
\text { razão entre a dívida externa e o PIB; Índice de instabilidade econômica } \\
\text { de Luporini e Alves (2010); taxa de inflação }\end{array}$ \\
\hline Outras medidas utilizadas & Carga tributária bruta. \\
\hline
\end{tabular}

Fonte: Os autores.

Não obstante as semelhanças apontadas, há pelo menos cinco clivagens importantes entre os textos desta literatura. Primeiramente, trabalhos que utilizam dados anuais devem ser separados dos que utilizam dados trimestrais - posto que regularidades empíricas diferentes podem ser encontradas em dados de frequências diferentes. No caso dos trabalhos com dados trimestrais, é útil também separar os textos que utilizam dados das contas nacionais referência 2000 dos que utilizam dados das contas nacionais referência 1985 - uma vez que as diferenças entre as duas referências são significativas. Em terceiro lugar, textos que se propõem a analisar especificamente a dinâmica de alguma medida de investimento no Brasil devem ser vistos de forma diferente de textos cujo objetivo principal é construir um modelo macroeconométrico completo aplicado aos dados brasileiros. Em quarto lugar, textos que desagregam a FBCF total da economia em FBCF em máquinas e equipamentos e construções devem ser separados dos que modelam a FBCF (privada ou total) da economia em termos agregados. Finalmente, é analiticamente útil também separar textos que procuram explicitamente identificar/remediar o problema do viés de endogeneidade - que se supõe endêmico em regressões entre as variáveis usualmente utilizadas nesta literatura - dos que não fazem isto ${ }^{7}$.

Dentre os textos citados por dos Santos e Pires (2009) e Luporini e Alves (2010) somente dos Santos e Pires (2007) atende simultaneamente aos requisitos de utilizar

\footnotetext{
${ }^{7}$ Poucos trabalhos tratam adequada e explicitamente da questão do viés de endogeneidade. Ribeiro e Teixeira (2001) é uma das exceções que confirmam a regra.
} 
dados trimestrais e utilizar dados das contas nacionais referência 2000 (disponibilizados pelo IBGE em $2007^{8}$ ). Estes requisitos são atendidos também nos trabalhos (mais recentes) de Sonaglio et al. (2010) e Minella e Souza-Sobrinho (2011). A Tabela 5 apresenta as especificações utilizadas e os resultados obtidos por estes trabalhos.

As especificações da Tabela 5 são sugestivas. Mas, até por construção, não fazem justiça aos principais fatos estilizados apresentados na segunda seção. Com efeito, as especificações são agregadas e, portanto, ignoram as dinâmicas distintas da FBCF em máquinas e equipamentos e construções (Gráfico 2). Ademais, enquanto Minella e Souza-Sobrinho (2011) ignoram inteiramente o papel do investimento público na dinâmica do investimento agregado, as conclusões de Dos Santos e Pires (2007) e Sonaglio et al. (2010) são prejudicadas pela má qualidade das estimativas utilizadas para a FBCF da APU nestes trabalhos'. Por fim, os três textos utilizam amostras inferiores a 50 observações.

Tabela 5: Estudos com dados trimestrais referência 2000

\begin{tabular}{|c|c|c|}
\hline Estudo & $\begin{array}{l}\text { Amostra/ } \\
\text { Metodologia }\end{array}$ & Especificação Proposta \\
\hline $\begin{array}{l}\text { Dos } \\
\text { Santos } \\
\text { e Pires } \\
(2007)\end{array}$ & $\begin{array}{l}\text { 1995:1-2006:4 } \\
\text { (Johansen) }\end{array}$ & 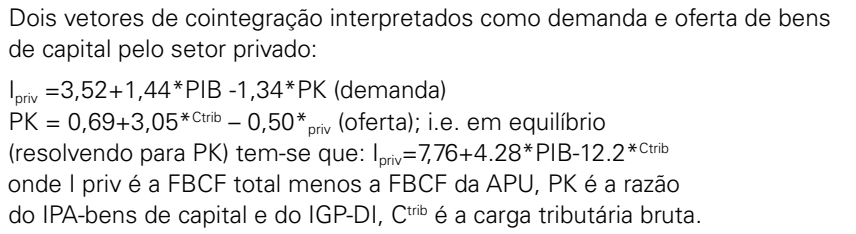 \\
\hline $\begin{array}{l}\text { Sonaglio } \\
\text { et al. } \\
(2010)\end{array}$ & $\begin{array}{l}\text { 1995:1-2006:4 } \\
\text { (Johansen) }\end{array}$ & $\begin{array}{l}\text { Um vetor de cointegração dado por: } \\
I_{\text {priv }}=11,61-0,43^{*} I_{\text {pub }}+3,53^{*} \text { PIB-3,3*PK- } 3,15^{*} C^{\text {trib }}-0,375^{*} \text { TJLP. } \\
\text { A notação é idêntica a de dos Santos e Pires ( } 2007) \text {, Ademais, Ipub é a FBCF } \\
\text { da APU e TJLP é a taxa de juros de longo prazo do BNDES (real, supõe-se). }\end{array}$ \\
\hline $\begin{array}{l}\text { Minella e } \\
\text { Souza- } \\
\text {-Sobrinho } \\
\text { (2011) }\end{array}$ & $\begin{array}{l}\text { 2000:2-2008:2 } \\
\text { (Mínimos } \\
\text { Quadrados } \\
\text { Ordinários) }\end{array}$ & $\begin{array}{l}I_{t}=0,566_{*} I_{t-1}-1,37_{*}\left(r_{t-1}^{s}-\pi_{t-1}^{e}{ }_{t+3}\right)+1,1_{*} y_{t-1}-0,36_{*}\left[\left(q_{t-1}+q_{t-2}\right) / 2\right]-2,15_{*} \Delta \phi_{t-3}+\varepsilon_{t} \\
\text { onde r é a taxa Swap-pré DI de } 360 \text { dias, } \pi^{e} \text { é a inflação esperada, } \Delta \phi \text { é a mu- } \\
\text { dança no prêmio de risco país, q é o preço relativo dos bens de investimento } \\
\text { (medido pela razão entre os deflatores da FBCF e do PIB* }), y \text { é o PIB, I é a } \\
\text { FBCF total da economia e } \varepsilon \text { é um ruído branco. De acordo com os autores "to- } \\
\text { das as séries (..) foram filtradas com o filtro de Hodrick-Prescott (HP), usando } \\
\text { o período 1996T1-2008T2 para reduzir o problema de início de amostra asso- } \\
\text { ciado ao filtro" }\end{array}$ \\
\hline
\end{tabular}

Fonte: Os autores.

* Minella e Souza Sobrinho (2011, p.59-60) notam que "o principal determinante do preço relativo dos bens de investimento é a taxa real de câmbio". Daí julgarem que que a formulação que adotam "é consistente com a evidência

\footnotetext{
${ }^{8}$ Dos Santos e Pires (2009) foi escrito em 2006 com dados referência 1985 e deve ser diferenciado de dos Santos e Pires (2007).

${ }^{9}$ Sonaglio et al. (2010) utilizam a mesma base de dados de Dos Santos e Pires (2007) e, portanto, a mesma medida da FBCF da APU utilizada em Dos Santos e Pires (2009). Mas Dos Santos e Pires (2009, p. 227) reconhecem explicitamente que suas "conclusões foram obtidas com dados aproximados e, portanto, devem ser vistas com cuidado" e reavaliadas, assim que possível, "de outras maneiras e com outros dados". Os dados propostos por Dos Santos et al. (2012) são significativamente melhores que os utilizados por Dos Santos e Pires (2009) e foram construídos precisamente para permitirem as referidas reavaliações.
} 
de que apreciações da taxa real de câmbio impulsionam a importação de máquinas e equipamentos e, portanto, o investimento no Brasil [...]. Entretanto, em vez de incluirmos a taxa de câmbio diretamente na equação de investimento, consideramos mais intuitivo modelar seus efeitos por meio do preço relativo dos bens de investimento."

Tabela 6: Estudos que desagregam a FBCF trimestral em máq. e equipamentos e construções

\begin{tabular}{|c|c|c|}
\hline Estudo & $\begin{array}{l}\text { Amostra/ Meto- } \\
\text { dologia }\end{array}$ & Especificações propostas \\
\hline $\begin{array}{l}\text { Cavalcanti } \\
(2003)\end{array}$ & $\begin{array}{l}\text { Não } \\
\text { explicitadas }\end{array}$ & $\begin{array}{l}\Delta \mathrm{im}_{\mathrm{t}}=-0,79+0,004 * \Delta \mathrm{u}_{\mathrm{t}-4}+0,005 * \Delta \mathrm{u}_{\mathrm{t}-6}-0,29 *(\mathrm{im}-\mathrm{y})_{\mathrm{t}-1}-0,0008_{*} \mathrm{r}_{\mathrm{t}-1} \\
\Delta \mathrm{ic}_{\mathrm{t}}=-0.24-0.86 * \mathrm{~T}+0.005 * \Delta \mathrm{u}_{\mathrm{t}-3}-0.22 *(\mathrm{ic}-\mathrm{y})_{\mathrm{t}-1}-0.0007 * \mathrm{r}_{\mathrm{t}-1} \\
\text { onde im e ic são, respectivamente, a FBCF em máquinas e equipamentos e } \\
\text { em construção, (im - y) e (ic }-\mathrm{y} \text { ) são termos de correção de erros que garan- } \\
\text { tem que im e ic crescem à mesma taxa que o PIB (y) no longo prazo, u é o } \\
\text { grau de utilização da capacidade (industrial, presume-se), } \mathrm{r} \text { é a taxa de juros } \\
\text { real e T é a carga tributária bruta. }\end{array}$ \\
\hline $\begin{array}{l}\text { Muinhos } \\
\text { e Alves } \\
\text { (2003) }\end{array}$ & $\begin{array}{l}\text { 1995:1-2002:2 } \\
\text { (Mínimos Qua- } \\
\text { drados Ordiná- } \\
\text { rios) }\end{array}$ & $\begin{array}{l}\mathrm{IM} \mathrm{I}_{\mathrm{t}}=-1,458+0,497 * \mathrm{IM} \mathrm{I}_{\mathrm{t}-1}-1,625_{*} \mathrm{r}^{\mathrm{swap} 6}{ }_{*} \mathrm{D} 2000+\text { dummies sazonais } \\
\mathrm{IC} \mathrm{C}_{\mathrm{t}}=-1,393+0,336_{*} \mathrm{I} \mathrm{C}_{\mathrm{t}-1}-1,01_{*} \mathrm{r}^{\mathrm{swap} 6}-2,3_{*}{ }^{\mathrm{rswap} 6} \text { *D1996 + dummies sazonais, } \\
\text { onde Im e Ic são, respectivamente, a FBCF em máquinas e equipamentos e } \\
\text { em construção ambas divididas por uma proxy da renda disponível potencial, } \\
\text { rswap6 é a taxa de juros real anualizada do Swap-pré DI de } 180 \text { dias e D1996 } \\
\text { e D2000 são respectivamente dummies de nível iguais a } 1 \text { a partir destes } \\
\text { anos. Muinhos e Alves notam, ainda, uma mudança na sazonalidade de am- } \\
\text { bas as séries em 1999. }\end{array}$ \\
\hline $\begin{array}{l}\text { Lelis } \\
\text { (2005) }\end{array}$ & $\begin{array}{l}\text { 1992:1 - 2003:4 } \\
\text { (Johansen) }\end{array}$ & $\begin{array}{l}\text { Um vetor de cointegração dado por: } \\
\text { FBME }=59,75+3,41_{*} \mathrm{CFAM}+2,21_{*} \mathrm{CGOV}+1,36_{*} \mathrm{EX}-1,04_{*} \mathrm{IM}+0,02_{*} \mathrm{UCl}- \\
-0,04 * T E N D \text {, onde FBME é a FBCF em máquinas e equipamentos, EX e IM } \\
\text { são, respectivamente, importações e exportações, Cfam e Cgov são, res- } \\
\text { pectivamente, o consumo das famílias e do governo, TEND é uma tendência } \\
\text { determinística linear e UCl é o grau de utilização da capacidade (industrial, } \\
\text { presume-se). }\end{array}$ \\
\hline
\end{tabular}

Fonte: Os autores.

Igualmente interessantes para os nossos propósitos - a despeito de relativamente antigos e de utilizarem dados das contas nacionais referência 1985 e amostras pequenas - são os estudos de Muinhos e Alves (2003), Cavalcanti (2003) e Lelis (2005), que apresentam especificações desagregadas para a FBCF trimestral em máquinas e equipamentos e em construções. A Tabela 6 apresenta as especificações utilizadas e os resultados obtidos por estes trabalhos.

\section{DADOS E PROCEDIMENTOS ECONOMÉTRICOS}

Os dados utilizados neste trabalho aparecem listados na Tabela 7. A amostra compreende o período entre janeiro de 1996 e janeiro de 2013. 
Tabela 7: Variáveis utilizadas nas especificações econométricas deste trabalho

\begin{tabular}{|l|l|}
\hline Variável & Fonte \\
\hline $\begin{array}{l}\text { LN (logaritmo neperiano) dos índices de volume trimestrais da FBCF } \\
\text { em construção e em máquinas e equipamentos dessazonalizados }\end{array}$ & $\begin{array}{l}\text { Carvalho e Ribeiro } \\
\text { (2014) }\end{array}$ \\
\hline $\begin{array}{l}\text { LN da FBCF-APU a preços encadeados de 1995 (deflator da FBCF) } \\
\text { dessazonalizada }\end{array}$ & $\begin{array}{l}\text { Atualização de Dos } \\
\text { Santos et al. (2012). }\end{array}$ \\
\hline $\begin{array}{l}\text { LN do PIB e da FBCF total da economia a preços encadeados de 1995 } \\
\text { dessazonalizados }\end{array}$ & $\begin{array}{l}\text { IBGE: Contas Nacio- } \\
\text { nais Trimestrais }\end{array}$ \\
\hline LN do índice IBOVESPA deflacionado pelo IPCA & Ibovespa \\
\hline $\begin{array}{l}\text { Taxas mensais anualizadas de juros "reais" SELIC, TJLP e Swap-DI 360 } \\
\text { deflacionadas pelo IPCA }\end{array}$ & IPEADATA \\
\hline $\begin{array}{l}\text { LN do índice de taxa de câmbio efetiva real construído a partir do IPA-DI } \\
\text { Brasil Central do }\end{array}$ \\
\hline $\begin{array}{l}\text { LN do Índice geral do preço de commodities em dólares no mercado } \\
\text { mundial }\end{array}$ & FMI \\
\hline Nível de utilização da capacidade na indústria (NUCI) dessazonalizado & FGV \\
\hline $\begin{array}{l}\text { Carga tributária bruta } \\
\text { LN das "despesas de investimento" a preços encadeados de 1995 } \\
\text { (deflator da FBCF) das empresas estatais federais dessazonalizado }\end{array}$ & $\begin{array}{l}\text { Dos Santos e Costa } \\
\text { (2008) e Orair et al. } \\
\text { (2013) atualizado }\end{array}$ \\
\hline
\end{tabular}

Fonte: Os autores.

A análise gráfica dos dados evidenciou a possibilidade de quebras estruturais na maior parte das séries relevantes. Daí, aliás, a opção pela aplicação de testes de Lee e Strazicich (2003) - cuja hipótese nula é que as séries são random-walks com tendência e até duas quebras estruturais - a todas às variáveis com tendência. Foi possível rejeitar a hipótese nula em todas as medidas de investimento utilizadas exceto FBCF privada e FBCF em construções. A hipótese nula também foi rejeitada para as séries do preço das commodities internacionais, da carga tributária e do IBOVESPA, mas não para o PIB. As quebras (em datas diversas) se mostraram significativas em todos os casos, inclusive nas não rejeições. No caso das séries sem tendência - i.e., as várias medidas da taxa de juros, o grau de utilização da capacidade da indústria (NUCI) e a taxa de câmbio - foram aplicados testes ADF-t e, quando necessário, o teste de Franses e Haldrup $(1994)^{10}$. Foi possível rejeitar a hipótese nula de raiz unitária no caso da TJLP e do NUCI, mas não nas demais taxas de juros e na taxa de câmbio.

${ }^{10}$ O teste de Franses e Haldrup (1994) tem como objetivo controlar pela possibilidade de "rejeições espúrias" da hipótese nula de raiz unitária nos testes ADF-t por conta da existência de observações aberrantes nas séries (como, por exemplo, em 2008, p. 4). 
Tabela 8: Resultado de testes de cointegração selecionados

\begin{tabular}{|c|c|c|}
\hline Teste & Resultado & Relação de cointegração \\
\hline$E \& G$ & $\begin{array}{l}-3.12 \text { (rejeita não } \\
\text { cointegração a 10\%) }\end{array}$ & fbcf_priv $=14.67-0.956$ câmbio \\
\hline G\&H & $\begin{array}{l}-5.73 \text { (rejeita não } \\
\text { cointegração a 1\%) }\end{array}$ & $\begin{array}{l}\text { fbcf_priv }=-5.00+1.358_{*} \text { PIB }-0.264_{*} \text { câmbio (de } 1996: 1 \text { até } \\
2002: 1 \text { ); e } \\
\text { fbcf_priv }=-5.15+1.358_{*} \text { PIB }-0.264_{*} \text { câmbio (de } 2002: 2 \text { até } \\
2013: 1 \text { ) }\end{array}$ \\
\hline $\mathrm{G} \& H$ & $\begin{array}{l}-5.60 \\
\text { (rejeita não } \\
\text { cointegração a 1\%) }\end{array}$ & $\begin{array}{l}\text { fbcf_priv }=-3.79+1.273_{*} \text { PIB }-0.298_{*} \text { câmbio }-0.12_{*} \text { jur_selic } \\
\text { (de } 1996: 1 \text { até } 2002: 1 \text { ); e } \\
\text { fbcf_priv }=-3.94+1.273_{*} \text { PIB }-0.298_{*} \text { câmbio }-0.132_{*} \text { jur_selic } \\
\text { (de } 2002: 2 \text { até } 2013: 1 \text { ) }\end{array}$ \\
\hline $\mathrm{JOH}$ & $\begin{array}{l}24.97 \text { (rejeita não } \\
\text { cointegração a 17\%) }\end{array}$ & $\begin{array}{l}\text { fbcf_priv }=6.936+0.544_{*} \text { PIB }-0.723_{*} \text { câmbio } \\
\text { (Com VAR de partida de segunda ordem). }\end{array}$ \\
\hline $\mathrm{JOH}$ & $\begin{array}{l}43.75 \text { (rejeita não } \\
\text { cointegração a } 11 \% \text { ) }\end{array}$ & $\begin{array}{l}\text { fbcf_priv }=12.894+0.085 * \text { PIB }-0.759_{*} \text { câmbio }-1.274_{*} \text { jur_selic } \\
\text { (Com VAR de partida de quinta ordem). }\end{array}$ \\
\hline $\mathrm{G} \& H$ & $\begin{array}{l}-5.06 \text { (rejeita não } \\
\text { cointegração a } 5 \% \text { ) }\end{array}$ & $\begin{array}{l}\left.\text { fbcf_constr }=-0.310+0.407_{*} \text { PIB (de 1996:1 até } 2002: 1\right) ; \text { e } \\
\text { fbcf_constr }=-7.319+0.970_{*} \text { PIB (de 2002:2 até 2013:1) }\end{array}$ \\
\hline $\mathrm{G} \& H$ & $\begin{array}{l}-4.92 \text { (rejeita não } \\
\text { cointegração a } 5 \% \text { ) }\end{array}$ & $\begin{array}{l}\text { fbcf_constr }=-5.17+0.835_{*} \text { PIB }-0.074_{*} \text { câmbio (de 1996:1 } \\
\text { até } 2002: 1) ; \\
\text { fbcf_constr }=-5.33+0.835_{*} \text { PIB }-0.074_{*} \text { câmbio (de 2002:2 } \\
\text { até } 2013: 1 \text { ) }\end{array}$ \\
\hline
\end{tabular}

Fonte: Os autores.

Testes de cointegração de Engle e Granger (1987) e Gregory e Hansen (1996) foram, então, aplicados às variáveis I(1) - i.e., à FBCF privada e FBCF em construções, PIB, câmbio e juros reais SELIC e SWAP-DI 360. Fortes evidências de cointegração foram encontradas entre as séries da FBCF privada, taxa de câmbio (principalmente) e o PIB. Evidências mais fracas de cointegração entre estas últimas variáveis e as medidas de taxas de juros foram também encontradas assumindo-se a existência de uma quebra estrutural na relação entre o final de 2001 e o início de $2002^{11}$. As estimativas apresentaram os sinais previstos em todas as especificações relevantes. As evidências de cointegração entre a FBCF em construções, PIB e câmbio foram mais fracas e dependentes da existência de quebras estruturais, enquanto que as medidas de taxa de juros utilizadas neste trabalho aparentemente não cointegram com a FBCF em construções. A aplicação de testes de Johansen (1991) confirmou apenas parcialmente as conclusões dos testes anteriores - o que não chega a surpreender, tendo em vista a sensibilidade destes testes à existência de não

\footnotetext{
${ }^{11}$ Como nos lembra Cook (2004), os resultados dos testes de Gregory e Hansen (1996) devem ser vistos com cuidado na presença de quebras estruturais nas séries.
} 
linearidades nas séries (e.g. Leybourne e Newbold, 2003) e incongruências no VAR de partida (por conta, por exemplo, de quebras estruturais).

Os resultados da Tabela 8 reiteram algumas correlações clássicas e sugerem não linearidades importantes - notadamente a clara mudança na dinâmica das variáveis de investimento brasileiras nos primeiros anos da década passada - mas não permitem maiores avanços na identificação das causas da dinâmica das variáveis de investimento utilizadas. Dito de outro modo, não há qualquer bom motivo teórico para se supor que as relações explicitadas acima estejam livres do problema do viés da endogeneidade. Com efeito, aplicações dos testes de Johansen (1992) nos VECMs subjacentes rejeitam a hipótese de exogeneidade fraca (no sentido de Engle, Hendry e Richard, 1983) do PIB e da taxa de juros - ainda que não rejeitem (a $5 \%$ de significância), registre-se, a hipótese de exogeneidade fraca da taxa de câmbio.

Uma alternativa para contornar este viés de endogeneidade é a utilização, em regressões econométricas da função investimento, dos preços das commodities como instrumento para o PIB brasileiro, tendo em vista a alta correlação entre estas duas variáveis.

Ressalte-se, ainda, que a série da FBCF em máquinas e equipamentos - a melhor aproximação de que dispomos para a FBCF das empresas não financeiras mostrou-se estacionária, o que desautoriza sua inclusão em VECMs. Nesse caso, o vetor de variáveis a serem analisadas contém algumas séries estacionárias e outras não-estacionárias. Daí a opção por especificações VAR contendo simultaneamente variáveis I(0) e I(1) defendidas, dentre outros, por Sims, Stock e Watson (1990). Há, naturalmente, diversas especificações possíveis a partir de combinações das variáveis da Tabela 7. Foram privilegiadas especificações com variáveis que podem ser justificadas como exógenas ao investimento, para viabilizar a identificação da estrutura de relações contemporâneas identificação das funções de impulso-resposta. Por esse motivo, não foi considerado o PIB como parte do grupo de variáveis do VAR (Tabela 9).

Tabela 9: VARs selecionados com variáveis I(1) e I(0)

\begin{tabular}{|l|l|}
\hline Modelo & Variáveis utilizadas \\
\hline 1 - VAR (2) & FBCF máquinas e equipamentos, commodities, câmbio \\
\hline 2 - VAR (2) & FBCF total, commodities, câmbio \\
\hline 3 -VAR (5) & FBCF máquinas e equipamentos, commodities, FBCF da APU \\
\hline $4-$ VAR (2) & FBCF total, commodities, FBCF da APU \\
\hline 5 -VAR (4) & FBCF máquinas e equipamentos, commodities, FBCF da APU e câmbio \\
\hline $6-$ VAR (2) & FBCF total, commodities, FBCF da APU e câmbio \\
\hline
\end{tabular}

Fonte: Os autores 
Com efeito, e conquanto o Brasil possivelmente seja um "país grande" em diversos mercados mundiais de commodities (impactando, talvez, o preço destas commodities pelo lado da oferta), é difícil acreditar que o preço mundial das commodities em dólares reaja a choques contemporâneos na FBCF das empresas brasileiras. Por outro lado, a forma pela qual a FBCF da APU é estimada (pelo lado da demanda; ver segunda seção) faz com que seja largamente exógena com relação a choques contemporâneos na FBCF das empresas brasileiras (medida fundamentalmente pela ótica da oferta). Naturalmente, estes choques possivelmente afetam contemporaneamente o produto e as receitas tributárias e, por esta via, o espaço fiscal para os planos de investimento público. Mas, no mais das vezes, quando uma despesa de investimento é computada como FBCF da APU (i.e., quando o ativo relevante é incorporado ao balanço da APU) ela já percorreu um longo caminho orçamentário (Dos Santos et al. 2012), de modo que a medida de FBCF da APU utilizada neste trabalho (em acordo com as determinações do SNA 2008) reflete em grande medida safras de decisões de gasto passadas com maturidades distintas ${ }^{12}$. Por fim, também o câmbio parece reagir muito pouco em relação a choques contemporâneos no investimento, como evidenciado pelo resultado dos testes de exogeneidade fraca reportados acima - refletindo talvez a perda (o ganho) de importância dos fluxos de comércio (financeiros) na determinação do balanço de pagamentos e práticas de flutuação suja por parte do BACEN.

Daí que a estratégia de identificação utilizada em todos os casos consistiu em excluir a possibilidade de impactos contemporâneos: (i) de quaisquer variáveis domésticas nos preços internacionais de commodities; (ii) de quaisquer variáveis na FBCF da APU; (iii) da FCBF da APU e em máquinas equipamentos (ou total) na taxa de câmbio. Assumiu-se, ademais, que a FBCF em máquinas e equipamentos (total) é afetada contemporaneamente por todas as variáveis e que a taxa de câmbio é afetada contemporaneamente pelo preço internacional de commodities. As implicações destas hipóteses são apresentadas nos Gráficos 4 a 6 no caso da FBCF em máquinas e equipamentos (o caso da FBCF total é análogo).

Resumidamente, as principais conclusões destes exercícios são: i) choques positivos no preço internacional das commodities e na FBCF da APU afetam positivamente; e ii) choques positivos (i.e., desvalorizações) no câmbio afetam negativamente a FBCF em máquinas e equipamentos (total) brasileira.

A análise detalhada dos nexos causais ou dos canais subjacentes a estas relações é um desenvolvimento natural deste trabalho, mas é complexa o suficiente para justificar trabalhos adicionais. Assim, nos limitamos a apresentar algumas possíveis explicações para os nossos resultados.

A forte correlação positiva entre os preços das commodities (supostamente

\footnotetext{
12 Acrescente-se que as administrações públicas sempre podem atrasar o pagamento de bens de capital e/ou obras já adquiridos/finalizados por conta de problemas de fluxo de caixa.
} 
exógenos) e a FBCF em máquinas e equipamentos pode ter diversas explicações não implicando necessariamente um aumento na participação dos setores da agropecuária e da indústria extrativa na composição da FBCF em máquinas e equipamentos (algo que não parece ter ocorrido entre os anos de 2000 e 2009, vide Tabela 3). Alguns canais indiretos de transmissão podem explicar esse resultado. Por exemplo, o relaxamento da restrição externa ao crescimento econômico e a ampliação do mercado interno de consumo no período em estudo. O canal do financiamento parece ser particularmente relevante, tendo vista a correlação positiva dos preços das commodities com ingressos de capitais para investimento direto e em carteira (particularmente para compra de ações na Bovespa), verificada no período em análise.

Diferentemente do que apontam alguns dos estudos resenhados, a relação positiva entre o investimento privado (medido pela FBCF total) e investimento público (FBCF da APU) corrobora a hipótese de que há complementariedade - e não antagonismo - entre os investimentos público e privado.

Igualmente complexa e controversa é a relação negativa entre a taxa de câmbio real e a FBCF verificada nos dados trimestrais. A princípio, podemos imaginar pelo menos: i) um canal direto, pelo efeito custo do investimento - que se reduziria face ao barateamento das máquinas importadas decorrente de uma valorização cambial; e ii) um canal indireto, em que a valorização cambial refletiria um relaxamento da restrição externa - que, por sua vez, viabilizaria uma flexibilização da política monetária e, portanto, um maior crescimento da demanda agregada (consumo e investimento da APU e estatais, transferências e estímulo ao crédito) estimulando-se, assim, o investimento.

Além disso, a ocorrência dos efeitos balanço e riqueza (Krugman, 1999; Allen et al., 2010, entre outros) também pode explicar a relação negativa entre taxa de câmbio e FBCF, principalmente no curto e médio prazo. É elevada a participação do endividamento externo das empresas brasileiras - notadamente, mas não apenas, as grandes exportadoras. Assim, dependendo da magnitude do descasamento de moedas, uma desvalorização cambial pode afetar negativamente balanço patrimonial e/ou a rentabilidade de uma empresa. ${ }^{13}$

O efeito balanço atua, portanto, no sentido contrário do efeito sobre a receita decorrente de uma mudança na competitividade externa em resposta a uma variação na taxa de câmbio. ${ }^{14}$ Portanto, o resultado líquido de uma variação cambial depende da magnitude de cada um destes dois efeitos antagônicos. Assim, é possí-

\footnotetext{
13 Krugman (1999), por exemplo, ressalta: “[...] the role of balance sheet difficulties in constraining investment by entrepreneurs, and the impact of the real exchange rate on those balance sheets" (pp. 460-1). Ver, também, Gandolfo (2002, cap. 16).

${ }^{14}$ Uma elevação (redução) da taxa de câmbio aumenta (diminui) a competitividade dos produtos domésticos.
} 
vel que uma desvalorização afete negativamente a rentabilidade de uma empresa ${ }^{15}$ comprometendo, assim, sua capacidade de investimento.

Vale notar que o efeito balanço negativo (de uma variação na taxa de câmbio) sobre a rentabilidade tende a se manifestar de maneira mais rápida. Já o efeito competitividade positivo tende a correr de forma defasada no tempo. Assim, pelo menos em um primeiro momento, uma desvalorização cambial tenderia ser prejudicial ao investimento. ${ }^{16}$

O mesmo raciocínio vale para os bancos brasileiros, cuja parcela relevante do funding é de origem externa. Da mesma maneira, dependendo da magnitude do descasamento de moedas, uma desvalorização cambial pode impactar negativamente o fluxo de caixa, a situação patrimonial e, também, a liquidez dos bancos. Assim, uma desvalorização pode reduzir a oferta de crédito doméstico (principalmente no curto/médio prazo), comprometendo-se, também, a FBCF.

O que importa salientar é que nossos resultados não indicam a existência de relação positiva entre a taxa de câmbio e o investimento em maquinas e equipamentos. Somando essas evidências empíricas com o fato de que o setor que mais demanda máquinas e equipamentos é o setor serviços (essencialmente non-tradable), os resultados não favorecem a tese de que uma desvalorização teria impacto positivo sobre o investimento, notadamente em máquinas e equipamentos.

Gráfico 4: Respostas da FBCF em máquinas e equip. a choques nas variáveis do modelo 1

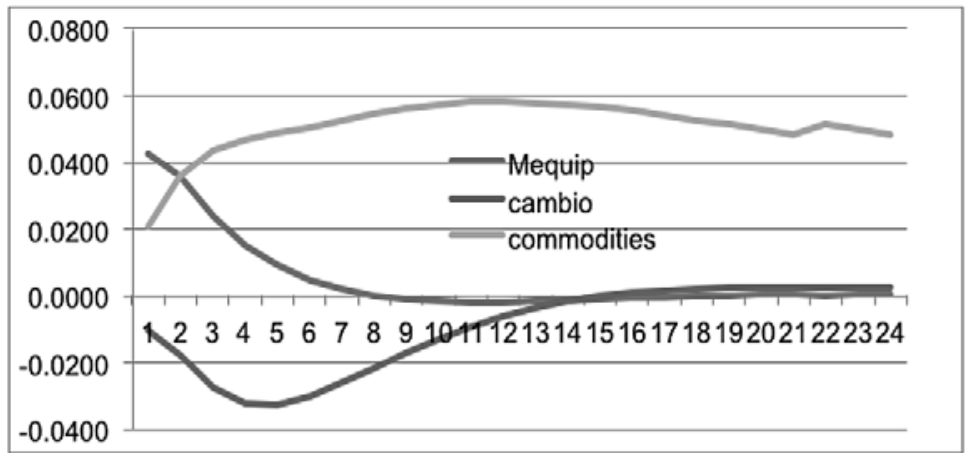

Fonte: Os autores.

15 Durante a crise do subprime (2008-2009), dois exemplos se mostraram notórios. Em face de expressiva desvalorização do real, a Aracruz e a Sadia, duas gigantes de seus respectivos setores, amargaram pesadas perdas com derivativos cambiais. Isso prejudicou, muito severamente, tanto a rentabilidade quanto a situação patrimonial das mesmas.

${ }^{16}$ A este respeito ver, por exemplo Valor (2014): “A expectativa dos analistas é que o ganho de receita com exportações [resultante da desvolrização do real] não será suficiente para cobrir o aumento da dívida neste momento. O grande impacto positivo virá nos próximos trimestre, se a moeda americana se mantiver alta" (Valor, 2014, p. B-1). 
Gráfico 5: Respostas da FBCF em máquinas e equip. a choques nas variáveis do modelo 3

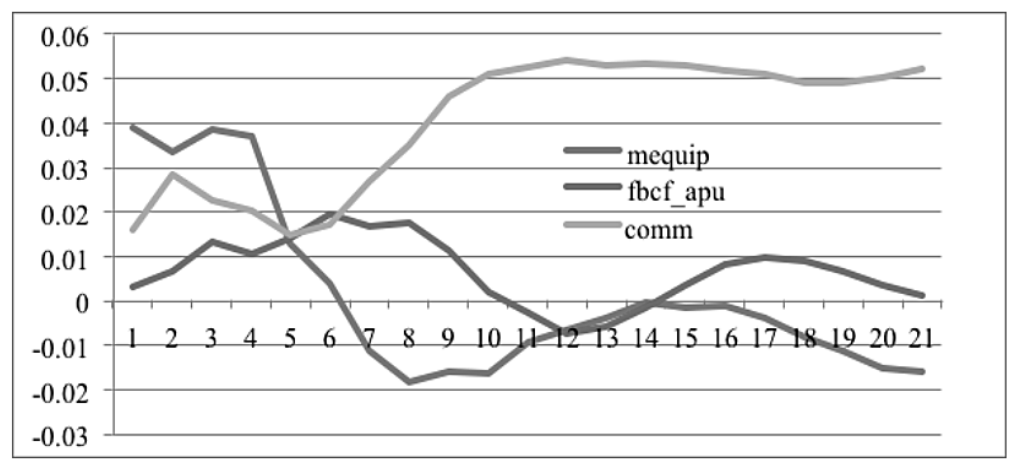

Fonte: Os autores.

Gráfico 6: Respostas da FBCF em máquinas e equip. a choques nas variáveis do modelo 5

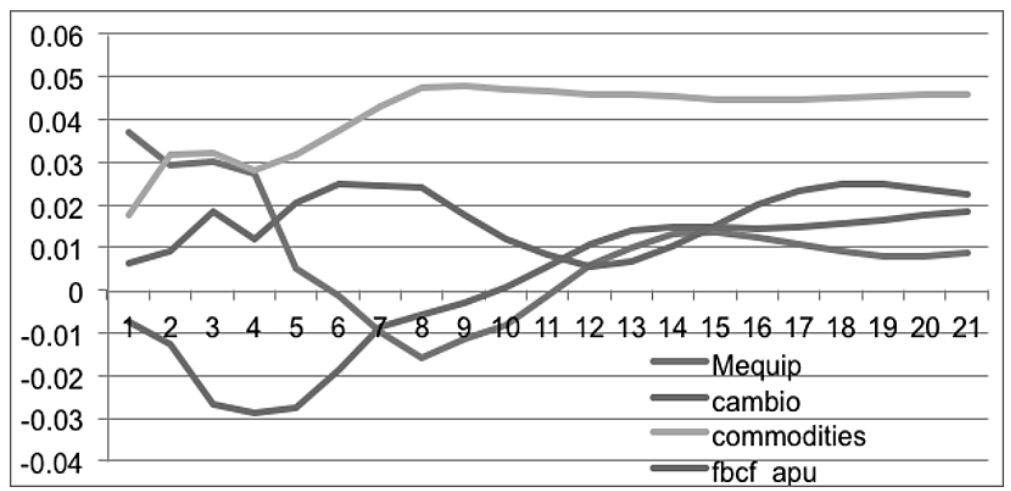

Fonte: Os autores

\section{NOTAS FINAIS}

Este trabalho revisitou a literatura sobre a dinâmica trimestral do investimento brasileiro, procurando: (i) discutir, de modo crítico, as características das estimativas da FBCF brasileira publicadas nas atuais contas nacionais (trimestrais), que subestimam o valor da FBCF efetiva da economia e são construídas com informações primordialmente do lado da oferta; (ii) complementar estas estimativas com outras - sobre a desagregação da FBCF em máquinas e equipamentos e construções (pelo lado da oferta) e em pública e privada (pelo lado da demanda) - igualmente informativas; e (iii) propor novas estratégias de identificação econométrica da dinâmica da FBCF no Brasil utilizando o preço internacional das commodities, a FBCF pública (construída com informações pelo lado da demanda) e a taxa de câmbio real como variáveis explicativas. 
Os resultados mostram claramente que a FBCF em máquinas e equipamentos - que mais se aproxima do conceito macroeconômico de investimento e, portanto, é mais reativa ao ambiente/ciclo econômico - apresenta uma dinâmica muito diferente do comportamento da FBCF em construções, que é mais estável do que a primeira, devido à maior participação do investimento das famílias e do governo. Assim, ressalta-se a relevância da FBCF em máquinas e equipamentos na dinâmica da FBCF total da economia brasileira. Os resultados também corroboram a forte e robusta relação entre a FBCF e o PIB, fenômeno já identificado na literatura resenhada.

Nossas estimativas com base em dados trimestrais também sugerem que a FBCF total da economia brasileira apresenta: i) uma relação positiva com, ambas as variáveis, preço das commodities e FBCF da APU; e ii) negativa com a taxa de cambio.

A relação positiva entre FBCF e preço das commodities pode resultar do relaxamento da restrição externa ao crescimento econômico que se verificou durante o período analisado, marcado por um boom nos preços das commodities. Como fator explicativo, destaca-se o canal do financiamento, dada a correlação positiva dos preços das commodities com o fluxo de capitais (IDE e em carteira) para o Brasil.

Ressalta-se ainda a relação positiva entre o investimento privado (medido pela FBCF total) e investimento público (FBCF da APU), diferentemente do que apontam alguns estudos. Reforça-se assim, ideia de que há complementariedade - e não antagonismo - entre os investimentos público e privado.

Quanto à taxa de câmbio, os resultados também chamam a atenção. Em princípio, nossas estimativas não corroboram a tese do Novo Desenvolvimentismo, segundo a qual a valorização cambial tem sido um entrave fundamental ao crescimento da economia brasileira. Mas essa questão específica é suficientemente complexa e não faz parte do foco do nosso trabalho. Dentre possíveis razões para este fato, destaca-se o efeito balanço/riqueza que, ao menos no curto prazo/médio, pode explicar por que a FBCF em máquinas e equipamentos se reduz em resposta a uma desvalorização cambial. Até que ponto este mecanismo se sustentaria no longo prazo é uma questão que merece ser aprofundada.

Por fim, uma nota de cautela: os mecanismos de transmissão e/ou os nexos causais subjacentes aos resultados apresentados ainda precisam ser aprofundados em estudos subsequentes.

\section{REFERÊNCIAS BIBLIOGRÁFICAS}

Allen, M.; Rosenberg, C.; Keller, C.; Setser, B. e Roubini, Allen. (2010), “A Balance Sheet Approach to Financial Crisis". IMF Working Paper.

Bresser-Pereira, L.C. (2008), "Dutch disease and its neutralization: a Ricardian approach". Revista de Economia Política, 28(1), pp. 47-71.

Bresser-Pereira, L.C. (2010a). Novo-Desenvolvimentismo: uma proposta para a economia brasileira. Nueva Sociedad, pp. 58-72. 
Bresser-Pereira, L.C. (2010b). Globalization and Competition. Cambridge: Cambridge University Press

Cavalcanti, M.A.C. (2003). Chronological Development and Main Features of IPEA'S quarterly macroeconomic model. Em: Fukuchi, T; e Cavalcanti, M.A.C. (eds.) (2003) Modeling the Brazilian Economy: Macroeconomics, Social Security and Consumer Demand. Rio de Janeiro: IPEA.

Carvalho, L.; Ribeiro, F. (2014). Metodologia de cálculo do indicador mensal para a formação bruta de capital fixo. Texto Para Discussão [no prelo]. Rio de Janeiro: IPEA.

Conte Filho,C.G. (2008). Os Determinantes do Investimento Privado na Economia Brasileira 19552003. Dissertação de Mestrado. PUC-RS.

Cook, S. (2004). Spurious rejection by cointegration tests incorporating structural change in the cointegrating relationship. Applied Economics Letters 11, 879-884.

Engle, R.F. e Granger, C.W.J.(1987). Co-integration e error correction: representation, estimation, and testing. Econometrica, v. 55, n. 2, p. 251-276.

Engle, R.F; Hendry, D.F; e Richard, J.F.(1983). Exogeneity. Econometrica, Vol.51, pp. 277-304

Favero, C. (2001) Applied Macroeconometrics. Oxford: Oxford University Press.

Franses, P.H. e Haldrup, N. (1994). The effects of additive outliers on tests for unit roots and cointegration. Journal of Business and Economic Statistics, v. 12, p. 471-478.

Freitas, F.N.P; e Dweck, E. (2010). Matriz de Absorção de investimento e análises de impactos econômicos. In: David Kupfer; Mariano F. Laplane; Célio Hiratuka. (Org.). Perspectivas do Investimento no Brasil: temas transversais. 1ed.Campinas: Synergia, 2010, v. 4, p. 401-428.

Gandolfo, G. (2002), “International Finance and Open-Economy Macroeconomics” Berlin: Springer-Verlag.

Gregory e Hansen (1996). Residual-based tests for cointegration in models with regime shifts. Journal of Econometrics, v. 70, n. 1, p. 99-126.

IBGE (2008). Sistema de Contas Nacionais. Série Relatórios Metodológicos, n. 24. Rio de Janeiro: IBGE

Johansen, S. (1991). Estimation and hypothesis testing of cointegration vectors in Gaussian vector autoregressive models". Econometrica 59: 1551-1580

Johansen,S.(1992).Cointegration in Partial System and the Efficiency of Single Equation Analysis. Journal of Econometrics, Vol.52, n.3, pp.389-402

Krugman, P. (1999). "Balance Sheets, the Transfer Problem, and Financial Crises". International Tax and Public Finance, 6, pp. 459-472.

Lelis, M.T.C. (2005) Um Modelo de Investimento Aplicado ao Brasil. Dissertação de mestrado, IE-UFRJ.

Lee, J; Strazicich, M. C. (2003). Minimum LM unit root test with two structural breaks. Review of Economics and Statistics, 63, p.1082-1089, 2003.

Leybourne, S. e Newbold, P. (2003). Spurious rejections by cointegration tests induced by structural breaks. Applied Economics, 35, p. 1.117-1.121.

Luporini, V; e Alves, J. D. O. (2010) "Investimento Privado: uma análise empírica para o Brasil" Economia e Sociedade, v. 19, p. 449-475.

Miguez, T; Freitas, F.N.P; Squeff, G; Vasconcellos, L; e Moraes, T.(2013). Uma Proposta Metodológica para a Estimação da Matriz de Absorção de Investimentos (MAI) para o período 2000-2009. Texto para Discussão no prelo. Brasilia: IPEA.

Minella, A.; Souza-Sobrinho, N. (2011) Canais Monetários no Brasil sob a Ótica de um Modelo Semiestrutural. Em: Banco Central do Brasil. (2011). Dez Anos de Metas para a Inflação - 1999. 2009. Brasília: Banco Central do Brasil.

Muinhos, M.K. e Alves, S.A.L. (2003). Medium-Size Macroeconomic Model for the Brazilian Economy. Working Paper Series n.64. Brasília: Banco Central do Brasil.

Orair, R. O; Gobetti, S. W.; Leal, E. M.; Silva, W. (2013). Carga tributária brasileira - 2002/2012: Estimação e análise dos determinantes da evolução recente. Brasília: Ipea, 2013. (Texto para Discussão, no prelo).

Organização das Nações Unidas; Banco Mundial; OCDE; FMI; Comissão Européia.(1993). System of National Accounts 1993. Nova York: ONU. 
Organização das Nações Unidas; Banco Mundial; OCDE; FMI; Comissão Européia. (2008). System of National Accounts 2008. Nova York: ONU.

Ribeiro, M.B; e Teixeira, J. (2001). Análisis econométrico de la inversión privada en Brasil. Revista da CEPAL, n.74. Agosto. 159-173.

Dos Santos, C.H; e Costa, F. R. (2008). Uma metodologia de estimação da carga tributária bruta brasileira em níveis trimestrais. Economia Aplicada, v. 12, n. 4, p. 581-606.

Dos Santos, C.H; e Pires, M. C. (2007). Qual a sensibilidade do investimento privado a aumentos na carga tributária? Novas estimativas agregadas e desagregadas a partir dos dados das contas nacionais - Referência 2000. Texto para Discussão 1314. Brasília: IPEA.

Dos Santos, C.H; e Castro Pires, M. C. (2009). Qual a sensibilidade dos investimentos privados a aumentos na carga tributária brasileira? Uma investigação econométrica. Revista de Economia Política, vol. 29, no 3 (115), pp. 213-231, julho-setembro.

Dos Santos,C.H; Orair,R; Gobetti,S; Ferreira,A; Rocha,W; Silva,H; Britto,J.M. (2012). Estimativas Mensais da Formação Bruta de Capital Fixo Pública no Brasil 2002-2010. Economia Aplicada, v. 16, n. 3, 2012, pp. 445-473.

Sims, C; Stock, J; e Watson, M. (1990). Inference in Linear Time Series Models with some Unit Roots. Econometrica, Vol. 58, No. 1, January,113-144

Sonaglio, C; Braga, M; Campos, A. (2010) Investimento Público e Privado no Brasil: Evidências dos Efeitos Crowding-In e Crowding-Out no Período 1995-2006. EconomiA, Brasília(DF), v.11, n.2, p.383-401, mai/ago 2010.

Valor (2014). "Eleição e economia fraca pesam nos resultados do $3^{\circ}$ trimestre". Valor Econômico, p. B-1. 